\title{
Análise de Decisão e Valor da Informação
}

\author{
Raul A. Teixeira*, Lúcio T. dos Santos.
}

\section{Resumo}

O presente trabalho trata sobre o uso de Análise de Decisão e Valor da Informação para determinar se é financeiramente viável pagar por informações novas durante a tomada de decisões que envolvam investimentos, lucros e perdas. É tratado em específico o caso em que uma indústria petrolífera estuda se deve perfurar um poço de petróleo ou não, levando em consideração a possibilidade de adquirir dados sísmicos sobre o local a ser perfurado que podem melhorar o seu conhecimento sobre as probabilidades de haver pétroleo.

\section{Palavras-chave: \\ Decisão, valor da informação, utilidade.}

\section{Introdução}

Quando se tomam decisões importantes, todas as possibilidades devem ser consideradas. Quando essas decisões envolvem valores monetários, deve haver uma análise mais minuciosa ainda do problema. A Análise Estatística de Decisão fornece ferramentas para a resolução desses problemas.

O objetivo nesse projeto foi em primeiro lugar estudar as bases da Análise de Decisão, Valor da Informação e Teoria da Utilidade para depois aplicá-las na resolução de um problema na área de geofísica, estudando assim o funcionamento dessas ferramentas.

\section{Resultados e Discussão}

Consideremos que uma determinada empresa precisa decidir se deve ou não perfurar um poço de petróleo em um lugar específico, considerando que há probabilidades de o poço estar seco ou possuir petróleo pesado, médio ou leve, que são seus possíveis estados naturais. Além disso, a empresa leva em consideração a possibilidade de pagar por algumas medições sísmicas do solo que vão modificar as probabilidades do estado natural do poço, indicando propensão à existência de petróleo ou não.

Assumindo que a empresa tem informações iniciais sobre o local (Tabela 1) e que o experimento é relativamente preciso (tabela 2), e construindo lucros baseando-se em valores reais de gastos da Petrobras no Pré-Sal em $2013^{3}$ (tabela 3), calcula-se o valor esperado do lucro com e sem a compra das informações, o que permite calcular o valor máximo a se pagar por elas.

Com os valores adotados, sem as medições, o valor esperado do evento é de US\$16 milhões. Com as medições, o valor esperado é de US\$26,5 milhões. Assim, o valor máximo a se pagar pelas medições sísmicas é de US\$10,5 milhões. Ou seja, pagando até no máximo esse valor, é vantajoso comprar as informações. Além disso, se o resultado for "propenso a petróleo", deve-se perfurar o solo com esperança de lucro de US\$50 milhões. Do contrário, não se deve perfurá-lo.

Tabela 1. Probabilidades a priori dos Estados Naturais.

\begin{tabular}{|l|c|}
\hline Estado Natural & Probabilidades \\
\hline Poço seco & 0,35 \\
Petróleo pesado & 0,35 \\
Petróleo médio & 0,20 \\
Petróleo leve & 0,10 \\
\hline
\end{tabular}

Tabela 2. Probabilidades de Resultado das Medições Sísmicas dado o Estado Natural.

\begin{tabular}{|l|cc|}
\hline \multirow{2}{*}{ Estado Natural } & \multicolumn{2}{|c|}{ Resultados das Medições } \\
\cline { 2 - 3 } & Propenso & Não propenso \\
\hline Poço seco & 0,10 & 0,90 \\
Petróleo pesado & 0,70 & 0,30 \\
Petróleo médio & 0,80 & 0,20 \\
Petróleo leve & 0,90 & 0,10 \\
\hline
\end{tabular}

Tabela 3. Pagamentos dos Estados Naturais.

\begin{tabular}{|l|c|}
\hline Estado Natural & Pagamentos (milhões de US\$) \\
\hline Poço seco & -60 \\
Petróleo pesado & 50 \\
Petróleo médio & 60 \\
Petróleo leve & 75 \\
\hline
\end{tabular}

\section{Conclusões}

A Análise Estatística de Decisão pode auxiliar na tomada de decisão e evitar gastos desnecessários, além de aumentar o lucro em geral de empresas das mais diversas áreas. Apesar de ter sido resolvido um problema relativamente simples, pode-se modificá-lo para questões mais complexas, como decidir um local dentro de determinada região para perfurar um poço, e envolver inúmeros experimentos e medições com respectivos custos.

\section{Agradecimentos}

- Conselho Nacional de Desenvolvimento Científico e Tecnológico (CNPq - agência de fomento);

- Ao Prof. Dr. Lúcio Tunes dos Santos, pela paciência em me orientar e pelos conhecimentos passados.
${ }^{1}$ BEKMAN, O. R.; NETO, P. L. O. C. Análise Estatística da Decisão. São Paulo: Edgard Blücher, 1980.

2 RAVINDRAN, A; PHILLIPS, D. T.; SOLBERG, J. J. Operations Research: Principles and Practice. Ed. 2. Canadá: John Wiley \& Sons, 1987.

${ }^{3}$ Reduzimos em $55 \%$ o tempo de perfuração de poços no pré-sal. Petrobras, 01 de jul. de 2014. Disponível em: <http://www.petrobras.com.br/fatos-edados/reduzimos-em-55-o-tempo-de-perfuracao-de-pocos-no-pre-sal.htm>.

Acesso em: 08 de jul. de 2019. 